\title{
Pengaruh Beban Penggilingan terhadap Kuat Tarik Kertas Seni dari Tandan Kosong Nipah dan Pelepah Pisang
}

\author{
Agung Eko Sucahyono \\ Balai Besar Kerajinan dan Batik, Jl. Kusumanegara 7, Yogyakarta, Indonesia
}

Diterima : 24 Juni 2020, Revisi akhir : 16 November 2020, Disetujui terbit : 30 Desember 2020

\section{Effect of Refining Load on The Tensile Strength of Nypa and Banana Trunk Art Paper}

\begin{abstract}
The use of non-wood materials as an alternative in making of art paper is needed. However, the quality of the resulting paper is often quite low in terms of its tensile strength. One of the tools used to improve the quality of art paper is a beater machine. This research used nypha and banana trunk as raw material. This study aims to determine the relationship between the addition of load on the beater machine to the tensile strength of art paper. The method used is a randomized complete design with independent variables of variations in mixture and weight of loading on the beater machine. The results showed that the loading of the beater machine had an effect on improving the quality of art paper, while the composition of the material did not significantly affect the quality of the paper. Optimal paper quality was obtained from the proportion of nypa and banana trunk of 60\%:40\% and load weight of $3.9 \mathrm{~kg}$, where the tensile strength was $4.24 \mathrm{kN} / \mathrm{m}$ or $4,240 \mathrm{~N} / \mathrm{m}$.
\end{abstract}

Keywords: art paper, beater machine, nypa

\begin{abstract}
Abstrak
Penggunaan bahan non-kayu sebagai alternatif dalam pembuatan kertas seni sangat dibutuhkan. Namun, kualitas kertas yang dihasilkan seringkali cukup rendah dari sisi kekuatan tariknya. Salah satu alat yang digunakan untuk meningkatkan kualitas kertas seni adalah beater machine. Penelitian ini menggunakan tandan kosong nipah (Nypa fruticans) dan batang pisang (Musa sapientum) sebagai bahan baku. Penelitian ini bertujuan untuk mengetahui hubungan antara penambahan beban pada mesin beater terhadap kuat tarik kertas seni. Metode yang digunakan adalah rancangan acak lengkap dengan variabel bebas yaitu variasi campuran dan berat pembebanan pada mesin beater. Hasil penelitian menunjukkan bahwa besar pembebanan pada mesin beater berpengaruh terhadap peningkatan kualitas kertas seni, sedangkan komposisi bahan tidak terlalu berpengaruh terhadap kualitas kertas. Kualitas kertas yang optimal diperoleh pada proporsi bahan baku pelepah nipah dengan campuran pelepah batang pisang 60\%:40\% dan berat pembebanan 3,9 kg, dengan nilai ketahanan tarik 4,24 kN/m atau $4.240 \mathrm{~N} / \mathrm{m}$.
\end{abstract}

Kata kunci: kertas seni, mesin beater, nipah 


\section{Pendahuluan}

Dewasa ini kertas tidak hanya digunakan sebagai alat untuk menyimpan tulisan saja, namun juga untuk berbagai kebutuhan lain. Kertas dapat digunakan sebagai pembungkus, pelapis bahkan dapat digunakan sebagai media karya seni yang dapat menunjukkan status sosial seseorang. Tingginya permintaan akan kertas ini tidak diimbangi dengan ketersediaan lahan di hutan, padahal kebanyakan kertas terbuat dari kayu. Penurunan luas hutan atau yang lebih dikenal dengan istilah deforestasi, merupakan dampak dari berkurangnya jumlah pohon yang menyebabkan jumlah $\mathrm{CO}_{2}$ di atmosfer yang diserap akan berkurang. Oleh karenanya deforestasi dapat dipandang sebagai penyebab pemanasan global (Astana et al., 2012). Kontradiksi dari kedua hal tersebut membuat perusahaan kertas harus mencari berbagai alternatif media penghasil kertas.

Kertas saat ini bukan hanya digunakan sebagai media informasi secara tertulis, melainkan juga sebagai media kreativitas dalam pembuatan karya seni yang bernilai tinggi. Kampanye isu lingkungan gencar dilakukan pemerintah, sehingga pembuatan pulp atau bubur kertas, dan kertas sebaiknya juga ramah lingkungan (Bahri, 2015). Salah satu syarat untuk dapat menggantikan kayu, maka bahan tersebut harus mempunyai panjang serat yang cukup. Panjang serat mempengaruhi sifat-sifat tertentu pulp dan kertas, termasuk ketahanan sobek, kekuatan tarik, dan daya lipat (Kardiansyah and Sugesty, 2014).

Banyak sekali bahan yang dicoba untuk menjadi bahan baku kertas; seperti sabut kelapa yang mengalami proses hidrolisis (Paskawati et al., 2010), alang-alang dengan proses asetosolv (Wibisono et al., 2011), ampas tebu dengan metode asetosolv (Allita et al., 2012) atau nipah dengan metode kimia (Wijana et al., 2013). Nipah merupakan tanaman yang sudah lama dimanfaatkan. Umumnya hanya daun nipah yang dimanfaatkan. Bagian nipah yang selama ini belum termanfaatkan diantaranya adalah pelepah tandan kosong. Pemanfaatan tandan kosong untuk bahan baku kertas sebelumnya pernah dilakukan untuk tandan kosong kelapa sawit (Anggraini and Roliadi, 2011). Hasil penelitian Mulyadi et al. (2014), pulp untuk kertas seni dari pelepah nipah mengandung serat yang cukup besar dengan kadar selulosa 38,90\%. Menurut Akpapan (2011), panjang serat nipah 1,06 mm.
Tanaman nipah biasanya terdiri atas 3-5 pelepah daun dengan panjang antara 5-7 $\mathrm{m}$. Jika dari 1 pohon nipah didapat pelepah sekitar $5 \mathrm{~kg}$, maka apabila 1 hektar terdapat kurang lebih 3000 pohon dapat diperkirakan ada 15 ton pelepah nipah per hektar/tahun (Akpakpan et al., 2011).

Selain nipah, pisang juga salah satu tanaman yang banyak dijumpai di daerah tropis. Berdasarkan data dari BPS produksi pisang di tahun 2018 sebanyak 7,26 juta ton. Batang pisang juga memiliki kualitas yang baik karena kandungan selulosa 83,3 \% (Bahri, 2017). Salah satu jenis pisang yang mempunyai serat panjang adalah pisang abaca. Pada umumnya produk kertas seni yang dikombinasikan dengan pelepah pisang abaka memiliki indeks sobek dan indeks retak yang lebih besar dibandingkan dengan kertas seni di pasaran (Mandegani et al., 2016). Kulit pisang kepok juga bisa menjadi bahan baku kertas yang cukup kuat (Novianti et al., 2016). Oleh karena ketersediaannya yang melimpah, maka nipah dan batang pisang sangat tepat untuk menggantikan bahan baku kertas yang biasanya berasal dari kayu.

Pada pembuatan pulp dan kertas menggunakan metodekimia denganproses soda, $\mathrm{NaOH}$ digunakan pada saat proses pemasakan. Penggunaan $\mathrm{NaOH}$ ini untuk mempermudah proses pendegradasian lignin dan mempercepat proses pelunakan dalam proses pembuatan pulp dan kertas. Kandungan lignin harus dikurangi karena sifat lignin yang menyebabkan kertas yang dihasilkan bersifat kaku dan mudah berubah warnanya. Dengan demikian kadar lignin yang rendah adalah lebih baik (dalam hubungannya dengan kualitas kertas). Konsentrasi $\mathrm{NaOH}$ juga dapat berpengaruh terhadap daya serap kertas terhadap alkali (Syamsu et al., 2014). Perbedaan konsentrasi ini juga dapat mempengaruhi jumlah rendemen.

Setelah melalui pemasakan, proses pembuatan pulp dilanjutkan dengan tahapan refining/ beating. Proses ini dapat menggunakan mesin beater. Prinsip kerja mesin ini adalah menggiling pulp dengan melewatkannya pada gerigi beater. Fungsi beban pada alat ini adalah untuk memperpendek jarak celah antara roda gigi beater dengan bagian dasar. Karena pada saat proses kerjanya selalu terendam air, maka mesin beater ini sebagian besar komponennya terbuat dari baja tahan karat (stainless steel). Hanya pada bagianbagian tertentu yang jarang terkena air saja yang terbuat dari besi. Penelitian ini bertujuan untuk mengetahui hubungan antara penambahan beban pada mesin beater terhadap kuat tarik kertas seni. 


\section{Bahan dan Metode}

Penelitian dilaksanakan di laboratorium Kertas Seni Balai Besar Kerajinan dan Batik Yogyakarta dan pengujian kertas dilakukan di Laboratorium Konservasi Kimia Biomaterial Fakultas Kehutanan Universitas Gadjah Mada Yogyakarta.

\section{Bahan}

Bahan-bahan baku utama yang digunakan dalam penelitian ini adalah pelepah nipah yang diperoleh dari Kabupaten Cilacap, Jawa Tengah; pelepah batang pisang sebagai campuran, yang diperoleh dari petani Kabupaten Magelang, Jawa Tengah; $\mathrm{NaOH}$ yang digunakan dengan konsentrasi $20 \mathrm{~g} / \mathrm{L}$ yang dicampurkan pada saat perebusan, air $20 \mathrm{~L}$ dan bahan baku padatan kering sebanyak $1 \mathrm{~kg}$.

\section{Metode}

\section{Rancangan Penelitian}

Penelitian dilakukan dengan menggunakan Rancangan Acak Lengkap (RAL) dengan dua faktor yaitu jumlah campuran (pulp pelepah batang pisang) dan berat pembebanan pada mesin beater.

Faktor I: Jumlah Pulp Pelepah Batang Pisang sebagai Campuran $(\mathrm{P})$

1. $\mathrm{P} 1=50 \%$ Pulp Pelepah Nipah : $50 \%$ Pulp Pelepah Batang Pisang

2. $\mathrm{P} 2=60 \%$ Pulp Pelepah Nipah : $40 \%$ Pulp Pelepah Batang Pisang

3. $\mathrm{P} 3=70 \%$ Pulp Pelepah Nipah : $30 \%$ Pulp Pelepah Batang Pisang

Faktor II: Berat Pembebanan pada mesin pencacah

1. $\mathrm{S} 1=3,9 \mathrm{~kg}$

2. $\mathrm{S} 2=2,2 \mathrm{~kg}$

Dengan demikian terdapat 6 variasi perlakuan yaitu 3 (P) x 2 (S), kemudian dilakukan ulangan sebanyak 3 kali sehingga jumlah unit percobaan, 6 (variasi perlakuan) x 3 (ulangan) $=18$ unit. Kemudian masing-masing variasi perlakuan dilakukan pengujian ketahanan tarik kertas. Perlakuan untuk tiap faktor dianggap sama, seperti sumber air, alat yang digunakan dan jenis timbangan. Berat bahan baku dihitung berdasarkan berat partikel kering udara, Faktorfaktor tersebut kemudian dikombinasikan sehingga memperoleh kombinasi P1S1, P1S2, P2S1, P2S2, P3S1, P3S2.

\section{Persiapan Bahan Baku}

Pelepah nipah dan pelepah batang pisang dicuci kemudian diangin-anginkan hingga kering sentuh. Lama pengeringan kurang lebih tiga minggu. Pelepah nipah dan batang pisang yang sudah kering kemudian dipotong secara manual menggunakan gunting, dengan ukuran $2-3 \mathrm{~cm}$

Bahan yang telah dipotong, ditimbang dan ditempatkan masing-masing pada plastik yang telah disiapkan. Dengan proporsi pelepah nipah $700 \mathrm{~g}$, sebanyak dua wadah; proporsi pelepah nipah 600 g, sebanyak dua wadah; proporsi pelepah nipah 500 g, sebanyak dua wadah dan proporsi pelepah batang pisang $300 \mathrm{~g}$, sebanyak dua wadah; proporsi pelepah batang pisang $400 \mathrm{~g}$, sebanyak dua wadah; proporsi pelepah batang pisang $500 \mathrm{~g}$, sebanyak dua wadah. Sehingga masing-masing bahan diperoleh enam proporsi bahan baku.

\section{Pemasakan}

Pelepah batang pisang dimasukkan bersama dengan $20 \mathrm{~L}$ air, ke dalam wadah (panci) kemudian dimasukkan $\mathrm{NaOH} 400$ g. Campuran bahan diaduk hingga semua bahan tercampur dan $\mathrm{NaOH}$ terlarut. Bahan dimasak hingga air mendidih. Proses pemasakan berlangsung selama 2 jam sejak air mendidih.

\section{Pencucian}

Bahan yang sudah lunak kemudian didinginkan selama sehari semalam. Selanjutnya bahan dicuci menggunakan karung plastik dengan cara dialiri air dan dibilas selama kurang lebih satu jam, sampai larutan $\mathrm{NaOH}$ benar-benar hilang dan air pencucian dari bahan tersebut tidak berwarna (bening).

\section{Penggilingan}

Bahan paduan yang sudah dicuci bersih kemudian digiling. Proses penggilingan 
dilakukan sebanyak dua kali yaitu menggunakan mesin crusher dan mesin beater.

\section{Penggilingan dengan Mesin Crusher}

Bahan yang telah dicuci bersih kemudian dimasukkan ke mesin crusher dan ditambahkan air hingga poros mesin crusher terendam. Kemudian dilakukan penggilingan selama 15 menit. Penggilingan pada mesin ini berfungsi untuk mencacah dan menghancurkan serat. Setelah proses penggilingan selesai, pulp kemudian dipindahkan ke bak penampungan.

\section{Penggilingan pada Mesin Beater}

Pulp yang terbentuk dimasukkan ke dalam mesin beater (Gambar 1) sebanyak 5 gayung dan ditambahkan air secukupnya, kemudian dilakukan penggilingan selama 5 menit dan setiap unit percobaan diberikan variasi pembebanan yaitu 3,9 kg dan 2,2 kg. Penggilingan yang kedua ini berfungsi untuk melumat dan memendekkan serat-serat pulp yang belum hancur saat digiling pertama, juga untuk memipihkan serat-serat. Untuk memberikan variasi pembebanan, maka mesin beater ini dilengkapi oleh tempat pin beban. Pin beban akan terhubung dengan plat yang ada di bawah roda gigi beater, sehingga jika beban ditambah maka plat akan naik dan celah antara plat dengan roda gigi beater akan berkurang. Demikian pula sebaliknya, jika beban berkurang maka plat akan turun dan celah akan membesar

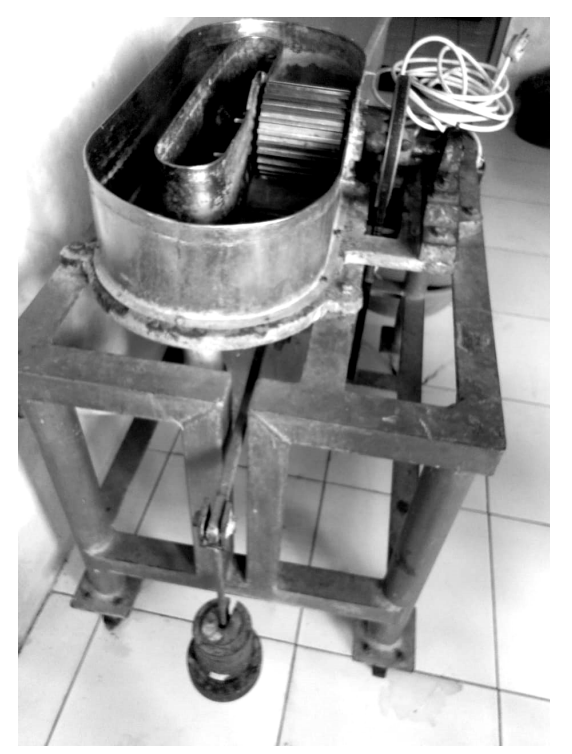

Gambar 1. Mesin Beater

\section{Pembuatan lembaran}

Pulp kemudian dicetak menjadi bentuk lembaran dengan menggunakan screen yang diberi pembatas, selanjutnya dicetak pada papan triplek berlapis kain yang sebelumnya sudah dibasahi dengan air. Fungsi dari pembatas screen tersebut agar pulp tidak lolos dan dapat berbentuk persegi sesuai dengan screen. Screen yang diberi pembatas tersebut kemudian direndam pada bak yang telah diisi air hingga $0,5 \mathrm{~cm}$ pembatas screen. Pada proses pembuatan lembaran dibutuhkan tiga gayung suspensi pulp untuk membuat satu lembar. Setiap satu gayung pulp dihamparkan secara merata pada screen yang telah diberi pembatas, hingga gayung pulp yang kedua dan ketiga. Setelah pulp merata pada screen, secara perlahan screen diangkat dari bak sambil ditiriskan, lalu diambil pembatasnya dan pulp siap untuk dicetak pada triplek yang telah dibasahi dengan air.

\section{Pengeringan dan Pengangkatan Lembaran}

Lembaran yang telah menempel pada triplek berlapis kain, dikeringkan dengan cara dijemur menggunakan panas sinar matahari. Proses penjemuran dilakukan hingga kering. Pada kondisi cuaca yang cukup panas, lembaran dapat kering sentuh dalam waktu satu hari. Bilamana lembaran sudah kering, didiamkan sekitar 10 menit, kemudian diangkat dari triplek yang dimulai dari ujung kertas secara perlahan-lahan agar tidak sobek. Lembaran kering ini disebut sebagai kertas seni.

\section{Pengujian Ketahanan Tarik}

Alat uji kekuatan tarik kertas terdiri atas 4 bagian utama yaitu celah penjepit kertas, bagian bergerak penarik kertas, motor penggerak dan pembaca skala. Langkah-langkah uji kekuatan kertas adalah sebagai berikut:

1. Komponen alat yang berfungsi sebagai bahan penarik kertas dan bagian statis disiapkan pada posisi masing-masing, kemudian motor penggerak dihidupkan. Bagian penarik dikunci dengan pengait agar tidak bergerak.

2. Kertas yang diuji, terlebih dahulu dipotong berukuran 10 x $5 \mathrm{~cm}$. Sampel kertas kemudian direntangkan diantara kedua celah penjepit dibagian statis dan bagian penarik. 
Sekrup pada masing-masing penjepit dirapatkan. Selanjutnya penjepit dilepas sehingga bagian penarik mulai bergerak untuk menarik kertas.

3. Angka yang pada skala yang terbaca pada bagian penarik tepat saat kertas terputus akibat tarikan, menunjukkan nilai kekuatan tarik kertas.

\section{Analisis Data}

Data hasil pengujian dianalisis dengan menggunakan Anova (Analisis of Variance) pada taraf 5\% dengan menggunakan program SPSS (Statistical Package for The Social Sciences) versi 16.0. Apabila terjadi perbedaan nilai analisis varian yang diuji, maka dilakukan uji lanjut dengan menggunakan metode Least Significant Difference (LSD).

\section{Hasil dan Pembahasan}

\section{Ketahanan Tarik}

Nilai hasil pengujian ketahanan tarik kertas disajikan pada Tabel 1. Sedangkan analisis sidik ragam yang dilakukan untuk mengetahui faktorfaktor yang berpengaruh terhadap ketahanan tarik kertas dapat dilihat pada Tabel 2. Berdasarkan Tabel 2 dapat dilihat bahwa faktor berat pembebanan berpengaruh terhadap ketahanan tarik kertas. Sedangkan faktor proporsi bahan dan interaksi antara proporsi bahan dan berat pembebanan tidak berpengaruh pada ketahanan tarik kertas.

Hasil pengujian untuk faktor proporsi bahan baku terhadap ketahanan tarik kertas pelepah nipah dengan campuran pelepah batang pisang menunjukkan proporsi bahan baku 50\%:50\%,
60\%:40\% dan 70\%:30\%. Nilai rata-rata ketahanan tarik dengan proporsi bahan baku 50\%:50\%, 60\%:40\% dan 70\%:30\% adalah 2,69 kN/m, 3,66 $\mathrm{kN} / \mathrm{m}$, dan $2,78 \mathrm{kN} / \mathrm{m}$. Nilai tersebut tidak berbeda nyata atau tidak berpengaruh terhadap ketahanan tarik. Sehingga semakin tinggi proporsi pulp nipah yang digunakan dalam pembuatan kertas seni ini, maka ketahanan tarik yang dihasilkan cenderung sama, tidak mengalami penurunan ataupun mengalami peningkatan.

Ketahanan tarik kertas seni dari pelepah nipah dengan campuran pelepah batang pisang pada

Tabel 1. Ketahanan Tarik (kN/m)

\begin{tabular}{|c|c|c|c|c|c|}
\hline \multirow{2}{*}{$\begin{array}{l}\text { Proporsi } \\
\text { PN : PBP } \\
(\%)\end{array}$} & \multirow{2}{*}{ (n) } & \multicolumn{2}{|c|}{$\begin{array}{c}\text { Berat Beban } \\
(\mathrm{kg})\end{array}$} & \multirow[t]{2}{*}{ Jumlah } & \multirow[t]{2}{*}{ Rerata } \\
\hline & & 3,9 & 2,2 & & \\
\hline \multirow{3}{*}{$50: 50$} & 1 & 1,27 & 2,60 & 3,87 & 1,93 \\
\hline & 2 & 3,33 & 3,47 & 6,80 & 3,40 \\
\hline & 3 & 3,20 & 2,27 & 5,47 & 2,73 \\
\hline Jumlah & & 7,80 & 8,33 & 16,13 & 8,07 \\
\hline \multirow[t]{2}{*}{ Rerata } & & 2,60 & 2,78 & 5,38 & 2,69 \\
\hline & 1 & 4,33 & 3,60 & 7,93 & 3,97 \\
\hline \multirow[t]{2}{*}{$60: 40$} & 2 & 3,33 & 2,67 & 6,00 & 3,00 \\
\hline & 3 & 5,07 & 2,93 & 8,00 & 4,00 \\
\hline Jumlah & & 12,73 & 9,20 & 21,93 & 10,97 \\
\hline \multirow[t]{2}{*}{ Rerata } & & 4,24 & 3,07 & 7,31 & 3,66 \\
\hline & 1 & 4,93 & 1,73 & 6,66 & 3,33 \\
\hline \multirow[t]{2}{*}{$70: 30$} & 2 & 2,67 & 1,60 & 4,27 & 2,13 \\
\hline & 3 & 4,13 & 1,60 & 5,73 & 2,87 \\
\hline Jumlah & & 11,73 & 4,93 & 16,66 & 8,33 \\
\hline Rerata & & 3,91 & 1,64 & & 2,78 \\
\hline Rt-Total & & 3,59 & 2,50 & & \\
\hline Total & & 32,26 & 22,47 & 54,73 & 27,37 \\
\hline
\end{tabular}

Keterangan :

PN : Pelepah Nipah

PBP : Pelepah Batang Pisang

Tabel 2. Analisis Varians Ketahanan Tarik Kertas

\begin{tabular}{lccccc}
\hline Sumber Keragaman & Jumlah Kuadrat & $\mathrm{Db}$ & Kuadrat Tengah & $\mathrm{F}_{\text {hit }}$ & Sig. \\
\hline Proporsi bahan & 3425150,77 & 2 & 1712575,389 & $2,546 \mathrm{~ns}$ & 3,89 \\
Berat Pembebanan & 5334466,72 & 1 & 5334466,722 & $7,930 *$ & 4,75 \\
Interaksi & 4500074,11 & 2 & 2250037,056 & $3,345 \mathrm{~ns}$ & 3,89 \\
Error & 8072016,00 & 12 & 672668,000 & & \\
Total & $1,878 \mathrm{E} 8$ & 18 & & & \\
\hline
\end{tabular}

Keterangan:

* = berbeda nyata

$n s=$ tidak berbeda nyata 
proporsi bahan baku 60\%:40\% dan 70\%:30\% mengalami penurunan. Sedangkan pada proporsi pelepah nipah dengan campuran pelepah batang pisang 50\%:50\% dan 60\%:40\% mengalami peningkatan. Hal tersebut diduga karena panjang serat yang terbentuk pada saat pulping mempengaruhi ikatan antar serat, dimana serat yang panjang mempunyai daya ikat serat yang lebih tinggi dibandingkan dengan serat yang pendek. Serat pelepah nipah mempunyai panjang kurang lebih 1,06 mm (Sugiarto, 2013) sedangkan batang pisang mempunyai ukuran panjang serat 4,20-5,46 mm (Nurrani, 2012). Ikatan antar serat yang terbentuk ini akan mempengaruhi ketahanan tarik, dimana semakin besar kekuatan ikatan antar serat maka ketahanan tarik juga makin besar.

Kualitas Kertas yang optimal diperoleh pada proporsi bahan baku pelepah nipah dengan campuran pelepah batang pisang 60\%:40\% dan berat pembebanan $3,9 \mathrm{~kg}$, dengan nilai ketahanan tarik $4,24 \mathrm{kN} / \mathrm{m}$ atau $4.240 \mathrm{~N} / \mathrm{m}$. Sedangkan kualitas kertas yang kurang optimal diperoleh pada proporsi bahan baku pelepah nipah dengan campuran pelepah batang pisang 70\%:30\% dengan berat pembebanan $2,2 \mathrm{~kg}$, dengan nilai ketahanan tarik $1,64 \mathrm{kN} / \mathrm{m}$ atau $1.640 \mathrm{~N} / \mathrm{m}$. Pada penelitian ini proporsi bahan tidak berpengaruh atau tidak berbeda nyata terhadap ketahanan tarik kertas, sehingga tidak perlu didakan uji lanjut atau uji Least Significant Difference (LSD).

Pada penelitian sebelumnya, telah menguji kekuatan tarik kertas nipah murni sebesar 1,14-2,15 kN/m (Sucahyono and Widiastuti, 2017). Jika dibandingkan dengan kekuatan kertas nipah murni, maka hasil pencampuran dengan pelepah batang pisang ini dapat menaikkan kekuatan tarik kertas. Sementara itu hasil penelitian Atsari, Wijana, Rahmah, and Sugiarto (2015), campuran nipah dengan kardus bekas dan memberikan perekat PVAc sebesar 5\% menghasilkan ketahanan tarik kertas seni sebesar 5,74 kN/m. Hasil ini lebih besar dibandingkan kertas seni dari nipah dan pelepah pisang. Menurut Pusat Informasi Obat dan Makanan, Badan POM RI, bahan perekat PVAc tetap mengandung unsur beracun terutama jika terhirup dapat mengakibatkan pneumonitis kimia (SIKerNas, 2012). Selain itu penambahan karton bekas juga sangat berbahaya, mengingat karton bekas tersebut bisa mengandung bahan-bahan berbahaya yang tidak terdeteksi sebelumnya. Selain itu pada karton bekas tentu sudah mengandung bahan perekat, baik itu PVAc maupun bahan perekat lainnya, sehingga kadar PVAc dalam kertas tersebut kemungkinan lebih dari 5\%. Untuk membandingkan dengan standar kualitas kertas, digunakan salah satu standar yaitu SNI 14-6519-2001 (Kertas dasar untuk kertas bungkus berlaminasi plastik), standar ketahanan tarik minimal 1,96 kN/m. Hal ini dilakukan mengingat kertas seni juga biasa digunakan sebagai pembungkus atau pelapis pada kotak. Melihat dari angka tersebut, maka sangat dimungkinkan paduan nipah dan pelepah batang pisang ini untuk pembuatan kertas.

\section{Aplikasi Ketahanan Tarik Kertas}

Diketahui bahwa kertas seni dari serat nipah mempunyai nilai ketahanan tarik yang lebih tinggi. Menurut Sucahyono and Widiastuti, (2017), kualitas kertas seni untuk dijadikan produk handycraft sangat penting dilihat dari ketahanan tarik. Semakin tinggi nilai ketahanan tarik suatu kertas seni, maka kualitas kertas yang dihasilkan semakin baik (tidak mudah sobek) khususnya sebagai bahan baku produk seperti kap lampu, kotak hias dan bingkai foto. Bahkan kertas seni dari nipah ini juga bisa digunakan untuk kertas cetak (print). Namun sangat disayangkan karena sistem pembuatannya yang masih manual, maka seringkali kekuatan tarik kertas ini belum seragam. Jika dilakukan penambahan volume pulp sehingga ketebalan kertas bertambah, maka diharapkan kekuatan tarik kertas ini akan bertambah.

\section{Kesimpulan}

Faktor berat pembebanan pada mesin penggilingan berpengaruh terhadap parameter pengujian ketahanan tarik kertas. Hal ini menunjukkan bahwa ketika akan melakukan pemrosesan kertas perlu dicari berat pembebanan yang optimal untuk masing-masing komposisi bahan baku. Berat pembebanan yang besar tidak otomatis membuat kualitas kertas menjadi lebih baik. Faktor proporsi bahan baku tidak berpengaruh terhadap parameter ketahanan tarik kertas. Semakin tinggi proporsi pulp nipah yang digunakan dalam pembuatan kertas seni, ketahanan tarik kertas yang dihasilkan cenderung sama, tidak mengalami penurunan ataupun mengalami peningkatan. 


\section{Saran}

Penelitian lanjutan sebaiknya mengevaluasi nilai gramatur, karena nilai gramatur sangat berpengaruh terhadap kekuatan tarik. Pengunaan bahan perekat ramah lingkungan bisa digunakan sebagai alternatif untuk menaikkan nilai kekuatan tarik. Selain itu, penelitian lebih lanjut untuk bahan-bahan pembuat kertas seni yang lain sehingga dapat diketahui pengaruh pembebanan yang sesungguhnya.

\section{Ucapan Terima Kasih}

Terima kasih kepada Ibu Tititk Purwati Widowati selaku kepala Balai Besar Kerajinan dan Batik yang telah memberi kesempatan dan arahan sehingga dapat dibuat penelitian ini. Juga kepada rekan-rekan di laboratorium kerajinan umum yang telah mendukung dan memberi semangat.

\section{Daftar Pustaka}

Akpakpan, A. E., Akpabio, U. D., Ogunsile, B. O., and Eduok, U. M. (2011). Influence of cooking variables on the soda and soda-ethanol pulping of Nypa fruticans petioles. Australian Journal of Basic and Applied Sciences.

Allita, Y., Gala, V., Citra, A. A., and Retnoningtyas, E. S. (2012). Pemanfaatan ampas tebu dan kulit pisang dalam pembuatan kertas serat campuran. Jurnal Teknik Kimia Indonesia, 11(2), 101. https://doi.org/10.5614/ jtki.2012.11.2.6

Anggraini, D., and Roliadi, H. (2011). Pembuatan Pulp Dari Tandan Kosong Kelapa Sawit Untuk Karton Pada Skala Usaha Kecil. Jurnal Penelitian Hasil Hutan, 29(3), 211-225. https://doi.org/10.20886/jphh.2011.29.3.211225

Astana, S., Sinaga, B. M., Soedomo, S., and Simangunsong, B. C. H. (2012). Macroeconomic Policy and Economic External Factor Impact on Natural Forest Degradation and Deforestation Rates: Case Study of Deforestation for Food and Estate Crops and Industrial Plantation Forest Areas Expansion and Degradation on Natural Forest Conces. Analisis Kebijakan Kehutanan, 9(3), $155-175$.

Atsari, I., Wijana, S., Rahmah, N. L., and Sugiarto, E. (2015). Ketahanan Tarik Kertas Seni dari Serat Pelepah Nipah (Nypa fruticans) (Kajian Proporsi Bahan Baku dan Perekat). September, 2-3. https://doi.org/10.13140/ RG.2.1.5174.3764
Bahri, S. (2015). Jurnal Teknologi Kimia Unimal Jurnal Teknologi Kimia Unimal Pembuatan Pulp dari Batang Pisang. In Jurnal Teknologi Kimia Unimal.

Bahri, S. (2017). Pembuatan Pulp dari Batang Pisang. Jurnal Teknologi Kimia Unimal, 4(2), 36. https://doi.org/10.29103/jtku. $\mathrm{v} 4 \mathrm{i} 2.72$

Kardiansyah, T., and Sugesty, S. (2014). Karakteristik Pulp Kimia Mekanis dari Kenaf (Hibiscus cannabinus L.) untuk Kertas Lainer. Jurnal Selulosa, 4(01), 3746. https://doi.org/10.25269/jsel.v4i01.55

Mandegani, G. B., Sumarto, H., and Perdana, A. (2016). Kertas Seni Berbahan Limbah Pewarna Alam Rumput Laut Jenis Sargassum, Ulva dan Pelepah Pisang Abaka. Dinamika Kerajinan Dan Batik: Majalah Ilmiah. https://doi.org/10.22322/ dkb.v33i1.1114

Mulyadi, A. F., Wijana, S., Arya, and Pratama, Y. (2014). Penggandaan Skala pada Pembuatan Pulp dari Pelepah Nipah (Nypa fruticans). Jurusan Teknologi Industri Pertanian Fakultas Teknologi Pertanian Universitas Brawijaya Jl. Veteran.

Novianti, P., Agustina, W., and Setyowati, E. (2016). Pemanfaatan Limbah Kulit Pisang Kepok Sebagai Bahan Baku Pembuatan Kertas Alami Dengan Metode Pemisahan Alkalisasi. Prosiding Seminar Nasional Pendidikan Sains.

Nurrani, L. (2012). Pemanfaatan Batang Pisang (Musa sp.) sebagai Bahan Baku Papan Serat dengan Perlakuan Termo-Mekanis. Jurnal Penelitian Hasil Hutan, 30(1), 1-9. https:// doi.org/10.20886/jphh.2012.30.1.1-9

Paskawati, Y. A., Susyana, Antaresti, and Retnoningtyas, E. S. (2010). Pemanfaatan sabut kelapa sebagai bahan baku pembuatan kertas komposit alternatif. Jurnal Widya Teknik, 9, 12-21.

SIKerNas. (2012). Polivinil Asetat (Issue 1).

Sucahyono, A. E., and Widiastuti, R. (2017). Nypha Stem Semi-Chemical Pulp: An Alternative Fiber Source for Art Paper. IUFRO-INAFOR Joint International Conference 2017, 445-452.

Sugiarto, E. (2013). Pemanfaatan Serat Nipah (Nypa fruticans) sebagai Bahan Baku Alternatif Kertas Seni (Kajian Proporsi Bahan Baku dan Perekat). Skripsi. Fakutas Teknologi Pertanian. Universitas Brawijaya.

Syamsu, K., Rolladi, H., Candra, K. P., and Arsyad, A. J. (2014). Kajian Proses Produksi Pulp dan Kertas Ramah Lingkungan dari Sabut Kelapa. Jurnal Teknologi Pertanian, 9(1). 
Wibisono, Leonardo, I., Hugo, Antaresti, and Aylianawati. (2011). Pembuatan Pulp Dari Alang-Alang. Widya Tenik, 10(1), 11-20.

Wijana, S., Rahmah, N. L., and Ansory, D. (2013). Studi Proses Pulping Serat Pelepah dan Serat Kulit Buah Nipah (Nypa fruticans) dengan Metode Kimia (Kajian Konsentrasi Larutan $\mathrm{NaOH})$. Jurnal Indsutria, 2(1). 